\title{
The Comparative Study of Antibacterial Activity Of Medicamental Composition For Temporary Placement Into Root Canals During Treatment Of Chronic Apical Periodontitis
}

\author{
${ }^{1}$ Anatoliy Borysenko, ${ }^{2}$ Serhiy Palamarchuk \\ ${ }^{1,2}$ Bogomolets National Medical University, Kiev, Ukraine
}

\begin{abstract}
SUMMARY
AIM: Studying the antibacterial properties of the medicamental composition for temporary placement into root canals during treatment of chronic apical periodontitis.

MATERIALS AND METHODS: Antibacterial properties of medicamental composition for temporary placement into root canals were determined by the degree of stunting test strains of microorganisms using the agar diffusion method.
\end{abstract}

RESULTS: medicamental composition for temporary placement into root canals possesses varying degrees of severity antibacterial properties on test strains of microflora.

Conclusions: medicamental composition for temporary placement into root canals suppresses the test strains of microflora reliably, and can be recommended for clinical treatment of chronic apical periodontitis.

KEY WORDS: medicamental composition for temporary placement into root canals, antibacterial action, test strains of microorganisms.

\section{INTRODUCTION}

The main objective of endodontic treatment of periodontitis is the most complete neutralization of pathogenic microflora in the system of teeth macro-and microcanals [1-4]. This is the key to suppression of inflammation in periodontal tissues, promoting regeneration of bone tissue in the source of inflammation and preventing the complications [ 5-9 ].In modern literature, much attention is paid to antibacterial agents to neutralize pathogenic microflora in the system of teeth macro-and microcanals. $(10,11)$. This is caused by lack of efficacy of antimicrobials on aerobic and anaerobic bacteria [12-16 ].To stimulate regeneration processes of periapical tissues a temporary paste for placement into root canals during treatment of chronic periodontitis is proposed. It contains an antibacterial drug which reliably suppresses anaerobic microflora - Metronidazole; a drug which removes fluid from the root canal and periodont - Enterosgel and a drug which stimulates the regeneration of bone tissue -Aflutop. Structure of the composition is as follows: Enterosgel - $610 \mathrm{mg}$, Metronidazole - $500 \mathrm{mg}$, Alflutop - $1 \mathrm{ml}$. This mixture of drugs has been blended in selected composition extempore to the consistency of paste. Given the significance of the microorganisms suppression in the treatment of periodontitis, the determination of antibacterial activity of the proposed medicamental composition is of utmost importance.

\section{THE AIM OF THE STUDY.}

The aim of this study is to determine the comparative antimicrobial action of the proposed medicamental composition on standard strains of microorganisms and mixed microflora of root canals of teeth with periodontitis.

\section{MATERIALS AND METHODS.}

The following drugs has been used for a comparative study of microflora sensitivity:

1. Medicamental composition for placement into root canals.

2. Metronidazole - $0.5 \%$-solution - anti-Trichomonas drug which effectively influences the anaerobic microflora.

3. Chlorhexidine - $0.05 \%$-solution - antiseptic of chlorine enclosing halogen composites.

4. Eton - $0.5 \%$-antiseptic of bisquartery ammonium composites group.

5. Myramistin $-0.01 \%$ - cationic surfactant substance with antiseptic properties. 


\section{Methods to determine the sensitivity of standard microorganisms strains to noted drugs.}

To determine the antibacterial action standard strains of microorganisms varying in taxonomic metric position and yeast fungi of the Candida genus have been selected. Reference test strains of organisms were obtained from the live cultures museum laboratory of the General Microbiology Institute of Kyiv Science and Research Institute of Epidemiology and Infectious Diseases of the National Academy of Medical Sciences of Ukraine.

Characteristics of microorganisms used are shown in the Table:

\begin{tabular}{|l|l|l|}
\hline Microorganisms & Number of strains & Sources of microorganisms \\
\hline S.aureus ATCC 25923 & 1 & $\begin{array}{l}\text { Live cultures museum of Kyiv Science and } \\
\text { Research Institute of Epidemiology and } \\
\text { Infectious Diseases named after } \\
\text { L.V.Hromashevskyi. }\end{array}$ \\
\hline E.coliATCC 001048 & 1 & $-/ /-$ \\
\hline Candidaalbicans ATCC 885653 & 1 & $-I I-$ \\
\hline
\end{tabular}

For medicamental forms which are poorly solved in the water and in the liquid nutrient environment, method based on the ability of drugs to penetrate into the thickness of the agar is used. To determine the antimicrobial action of the substances under research, agar diffusion method (method of "wells ") [17] has been used.Similarly sensitivity of the mixed microflora of root canals with periodontitis to the action of the drugs under study was being determined. The material for microbiological examination was taken from the root canals of patients treated with periodontitis . It was taken with root needle with sterile cotton pads. For this purpose carious cavity was dissected creating endodontic access to root canals. Root needle with sterile cotton pad was introduced into open root canal. After taking the material the pad was put into prepared $1 \%$ meat peptonic broth and placed in the thermostat for $24 \mathrm{~h}$ at temperature of $37^{\circ} \mathrm{C}$. Subsequently meat peptonic agar was prepared from it.Melted meat peptonic agar (MPA) with microorganisms (standard strains and mixed microflora) were poured in $20 \mathrm{ml}$ sterile Petri cups with a diameter of $100 \mathrm{~mm}$ placed on a horizontal surface.The surface of the stiffened meat peptonic agar was being dried during30-40 minutes at room temperature with half-open lids. Thus prepared Petri cups can be stored for a maximum of 7 days at $10^{\circ} \mathrm{C}$, before microflora sifting they had been dried. To determine the sensitivity of medicamental drugs pure culture inoculum of bacteria that had been grown on the surface of the meat peptonic agar was prepared. It was prepared from a suspension of $5-10$ isolated colonies in isotonic sodium chloride solution. The suspension was diluted to 10 units (according to standards of optical turbidity) and subsequently it was diluted 10 times more in isotonic sodium chloride solution. Immediately after preparation the inoculum in the volume of $2.1 \mathrm{ml}$ was applied to the surface of the dried agar in Petri cups and evenly distributed by jiggling the cups. The excess fluid was taken away with a pipette.

Half-open cups were being dried at room temperature during 10-15 minutes.Petri cupss in a horizontal position were filled with two layers of solid nutrient environment . The bottom layer - $10 \mathrm{ml}$ of melted "hungry" agar AGV , the top layer - nutrient environment for the corresponding daily culture of microorganisms test strains (for E.coli- meat peptonic agar (MPA), for S.aureus - MPA with the addition of $10 \%$ glucose ( glucose MPA ), for Candidaalbicans - Sabouraud environment ). After cooling of the bottom layer of agar, on it at the same distance from each other and from the edge of Petri cups holes with a diameter of $6 \mathrm{~mm}$ were prepared. For this purpose steel thin wlls cylinders (with inner diameter of $6.0+0.1 \mathrm{~mm}$ and height of $10.0+0.1 \mathrm{~mm}$ ) were set. Around cylinders were filled with the top layer $-13.5 \mathrm{ml}$ of melted and cooled to $45-48^{\circ} \mathrm{C}$ agar mixed with sifted dose of test microorganism ( $1.5 \mathrm{ml}$ of bacterial suspension of corresponding concentration) ( 3 ). After cooling the upper layer of agar cylinders were removed with sterile forceps and solution of studied drugs was placed into received holes. Petri cups with the material under study were preserved in thermostat during 24 hours at $37^{\circ} \mathrm{C}$ [ ]. Account of the results was done in 24 hours by identifying the areas of stunted microorganisms growth in $\mathrm{mm}$, including the diameter of the holes as well.

It was done considering the diameters of the areas of stunted microorganisms growth around the holes with antimicrobial drugs. Antibacterial activity of materials was evaluted by the size (in $\mathrm{mm}$ ) of the diameter of the areas of stunted microorganisms growth around each sample (Teteryna L.N., 1997). Evaluation of antibacterial activity was conducted according to the following criteria :

- 11 -14mm - slight antibacterial effect;

- 15 - 19mm - moderate antibacterial effect;

- 20 - 40mm - high antibacterial effect. 
Each of the experiments was repeated 7-8 times for statistical certainty. The average arithmetic mean for each of the studied groups of antibiotics was determined.

\section{RESULTS OF THE STUDY AND THEIR DISCUSSION.}

Evaluation of the received results was conducted on individual test cultures (Staphilococcusaureus, Escherichiacoli, Candidaalbicans) of microorganisms and on the action on the mixed microflora of root canals with chronic periodontitis. While the antibacterial agents studied were influencing test standard culture strain Staphilococcusaureus ( ATCC 27923 ) the areas of stunted microorganisms growth were as follows: medicamental composition for placement into root canals (1) from 12.4 to $17.3 \mathrm{~mm}$ (average of $14.6 \pm 016$ $\mathrm{mm}$ ), Metronidazole - $0.5 \%$ - solution of (2) - from $12.2 \mathrm{~mm}$ to $18.1 \mathrm{~mm}$ (average of $14.5 \pm 0,16 \mathrm{~mm}$ ), $0.005 \%$ Chlorhexidine solution ( 3 ) - from 17.4 to $22.3 \mathrm{~mm}$ (average $18.5 \pm 0.2 \mathrm{~mm}$ ), respectively. Eton - $0.5 \%$ solution (4), Miramistin $0.01 \%$ solution ( 5 ) were almost identical, rating from 16.6 to 21.5 mm (average of $18.5 \pm 0.14 \mathrm{~mm}$ ) and from 16.9 to $21.8 \mathrm{~mm}$ (average of $18,6 \pm 0,10 \mathrm{~mm}$ ), respectively - Fig. 1 .

Analyzing the results received in the studied group of the action of antimicrobials on Staphilococcusaureus according to existing bottom-up criteria of microbiological evaluation of sensitivity in points $(1,2,3)$, it can be affirmed that there was sufficient ( 2 points) and high (3 points) sensitivity of studied cultures to 4 antiseptics (Chlorhexidine, Eton, Myramistin ) and sufficient ( 2 points) sensitivity to the medicamentl composition for placement into root canals and $0.5 \%$ Metronidazole solution, but Chlorhexidine, Myramistin have the highest antibacterial activity against Staphilococcusaureus.

Determination of antibacterial action of the studied drugs in relation to test culture Escherichiacoli (ATCC 001048 ) showed the following sizes of the areas of stunted microorganisms growth: medicamental composition for placement into root canals (1 ) - from 12.0 to $27.1 \mathrm{~mm}$ (average of $16.5 \pm 0.16 \mathrm{~mm}$ ), $(1,2,3$ points); Metronidazole - $0.5 \%$ - solution (2) - from 8.1 to $26.2 \mathrm{~mm}$ respectively (average of $16.4 \pm 0.35 \mathrm{~mm}$ ), (1, 2.3 points ) $0.005 \%$ Chlorhexidine solution ( 3$)$, from 18.6 to $37.6 \mathrm{~mm}$ (average of $24.5 \pm 0.30 \mathrm{~mm})(2,3$ points ), Eton - $0.5 \%$ solution ( 4 ) - from 10.8 to $21.0 \mathrm{~mm}$, respectively (average of $14.6 \pm 0.22 \mathrm{~mm}),(1,2,3$ points); Miramistin $0.01 \%$ solution ( 5) - 10.6 to $20.1 \mathrm{~mm}$ (average of $15.6 \pm 0.18 \mathrm{~mm}),(1,2,3$ points) - Fig. 2 . Thus, the data obtained by microbiological studies suggest high antibacterial activity of all drugs in respect to test strain of Escherichiacoli. Determination of the impact of the studied drugs on the test strain fungi Candidaalbicans genus (ATCC885 663 ) found out the sufficient antibacterial activity, but the areas of stunted microorganisms growth were the smallest and amounted respectively to: medicamental composition for placement into root canals (1) - from 8.6 to $15,3 \mathrm{~mm}$ (average of $11.9 \pm 0.16 \mathrm{~mm}$ ), it is considered as sufficient sensitivity ( 2 points); Metronidazole - $0.5 \%$-solution (2) - from 9.2 to 14.5 (average of $11.9 \pm 0.22 \mathrm{~mm}$ (1 - 2 points); $0.005 \%$ Chlorhexidine solution (3), from 10.5 - $13.6 \mathrm{~mm}$ ( average of $12.5 \pm 0.24 \mathrm{~mm}$ ), respectively (12 points); Eton -0, $5 \%$ solution (4) - from 14.3 to $18.5 \mathrm{~mm}$ (average of $16.5 \pm 0.25 \mathrm{~mm})$ (2, 3 points); Miramistin - $0.01 \%$ solution ( 5 ) - from 12.3 to $17.5 \mathrm{~mm}$ (average of $13.6 \pm 0.15$ ) ( 2, 3 points), Fig. 3. In general, the studied drugs exert sufficient antifungal activity, meaning average positive result has been received.

It is important to determine the antibacterial activity of the studied drugs in relation to the mixed microflora of root canals with chronic periodontitis for clinical use. The following results of microbiological research were received: medicamental composition for placement into root canals (1) - from 25.2 to $32.2 \mathrm{~mm}$ (averge of 29.8 $\pm 0.27 \mathrm{~mm}$ ) (3 points), Metronidazole - $05 \%$-solution (2), from 23.2 to $34.1 \mathrm{~mm}$, respectively (averge of $28.6 \pm$ $0.24 \mathrm{~mm}$ ) (3 points), $0.005 \%$ Chlorhexidine solution ( 3 ) - from 24.3 to $35.7 \mathrm{~mm}$, respectively (average of 30.6 $\pm 0.24 \mathrm{~mm})(3$ points); Eton - $0.5 \%$-solution - from 11.7 to $20.0 \mathrm{~mm}$ (average of $13.6 \pm 0.26 \mathrm{~mm})(1-2$ points); Miramistin - $0.01 \%$-solution - from 15.8 to $21.2 \mathrm{~mm}$ (average of $18.3 \pm 0.27 \mathrm{~mm}$ ) (2 points),

Fig. 4 .Generalized results of microbiological studies are presented in the Table 1.

Table 1.Areas of stunted microorganisms growth in $\mathrm{mm}(\mathrm{M}+\mathrm{m})$ Staphilococcusaurens, Escherichiacoli, Candidaalbicans and mixed microflora of teeth root canals.

\begin{tabular}{|c|c|c|c|c|}
\hline \multirow[b]{2}{*}{ Studied drugs } & \multicolumn{4}{|c|}{ Test cultures of microorganisms } \\
\hline & $\begin{array}{l}\text { Staphilococcusaurens(ATCC } \\
\text { 27923) }\end{array}$ & $\begin{array}{l}\text { Escherichiacoli(ATCC } \\
001048)\end{array}$ & $\begin{array}{l}\text { Candidaalbicans(ATC } \\
\text { C 885663) }\end{array}$ & Mixed microflora \\
\hline $\begin{array}{l}\text { 1.Medicamental composition for } \\
\text { placement into root canals }\end{array}$ & $14.6 \pm 0.16$ & $16.5 \pm 0.16$ & $11.9 \pm 0.16$ & $29.8 \pm 0.27$ \\
\hline 2. Metronidazole $-0,5 \%$ - solution & $14.5 \pm 0.16$ & $16.4 \pm 0.35$ & $11.9 \pm 0.22$ & $28.6 \pm 0.24$ \\
\hline 3. Chlorhexidine - $0,005 \%$ solution & $18.5 \pm 0.2$ & $24.5 \pm 0.30$ & $12.5 \pm 0.24$ & $30.6 \pm 0.24$ \\
\hline 4. Eton $-0,5 \%$ solution & $18.5 \pm 0.14$ & $14.6 \pm 0.22$ & $16.5 \pm 0.25$ & $13.6 \pm 0.26$ \\
\hline 5.Miramistin- $0,01 \%$ solution & $18.6 \pm 0.10$ & $15.6 \pm 0.18$ & $13.6 \pm 0.15$ & $18.3 \pm 0.27$ \\
\hline
\end{tabular}




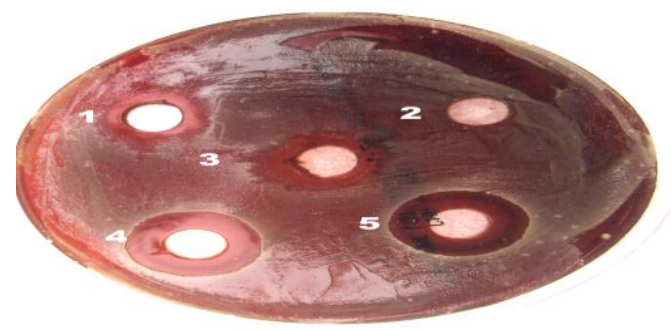

Figure 1

Areas of stunted growthof test cultures of Staphilococcusaurens

1. Medicamental composition for placement into root canals

2. Metronidazole $-0.5 \%$ - solution

3. Chlorhexidine $-0.005 \%$ - solution

4. Eton- $0.5 \%$ - solution

5. Miramistin- $0.01 \%$-solution

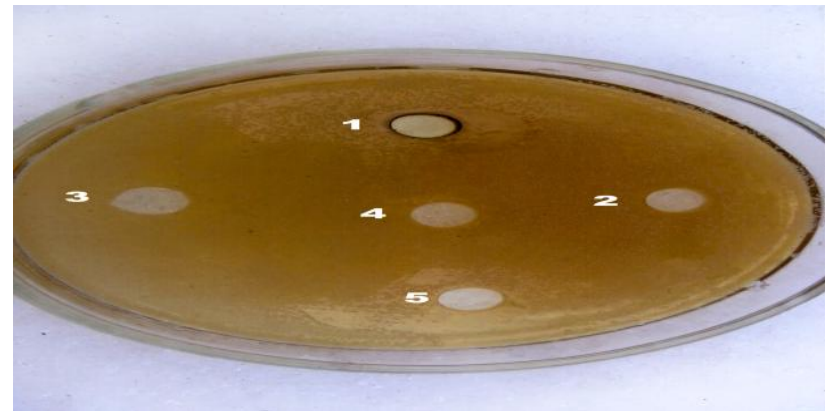

Figure 2

Areas of stunted growth of test cultures of Escherichiacoli

1. Medicamental composition for placement into root canals

2. Metronidazole $-0.5 \%$ - solution

3. Chlorhexidine $-0.005 \%$ - solution

4. Eton- $0.5 \%$ - solution

5. Miramistin- $0.01 \%$-solution

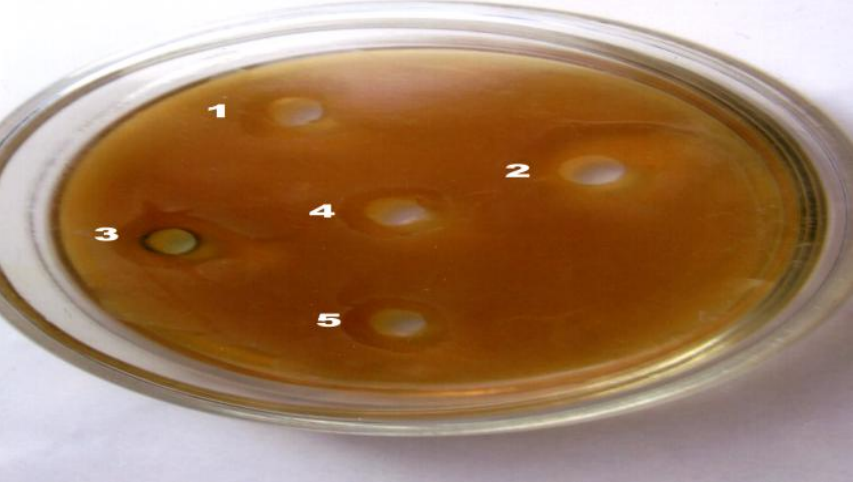

Figure 3

Areas of stunted growth of test cultures of Candidaalbicans

1. Medicamental composition for placement into root canals

2. Metronidazole $-0.5 \%$ - solution

3. Chlorhexidine $-0.005 \%$ - solution

4. Eton- $0.5 \%$ - solution 
5. Miramistin- $0.01 \%$-solution

Figure 4

Areas of stunted growth of mixed microflora of root canals

1. Medicamental composition for placement into root canals

2. Metronidazole $-0.5 \%$ - solution

3. Chlorhexidine $-0.005 \%$ - solution

4. Eton - $0.5 \%$ - solution

5. Miramistin - $0.01 \%$-solution

\section{REFERENCES}

[1] Bazhanov E.N., Kozlov V.A., Robustova T.H. , Maksymovskiy Y.M., Dentistry - 1997

[2] Balyn V.N., Yordanishvili A.K., Kovalevskiy, Practical periodontology (St. Petersburg: PITER, 1995).

[3] Borovsky E.V., Problems of endodontics according to survey, Clinical Dentistry, 1998, 1, 6-9.

[4] Borovsky E.V., Clinical Endodonty (M.: AO Dentistry , 1999).

[5] Borovsky E.V. Mistakes and complications of endodontic treatment, News "Densplay".- 8, 2003, 8-11.

[6] Maksymenko P.T., Side effects of drugs in dental practice (Poltava , 2004).

[7] Ovrutskiy G.Y., Hemonov V.V., Chronic odontogenic focus (Moscow , Medicine , 1993).

[8] Pedorets A.P , Pilyaev A.G., Pedorets N.A., Predictable Endodonty ( Donetsk: Nord -Press, 2006).

[9] Pedorets A.P, Donskyy G.I., Petrov S.N., Clinical aspects of modern endodonty , Dentist ,2, 2001, 33-34

[10] Budevskaya T.V., Sobeschuk O.P., Bratus I.N., Adarchenko V.A., The role of optional aerobic microorganisms in aetiology of apical periodontitis , Belarus health service , 7,1991,37 -40.

[11] Levkovich A.N., Study of microflora of periapical tissues during separate periods after periodontitis treatment, Dentistry, 2 , 1986, 18-19.

[12] Gimaev L.N., Melnikov V.G., Dynamics of clinical and bacteriological data in light treatment of upper periodontitis, GNL // MMSI.M. -1989 Dep .: VNPOSoyuzmedinform, № I873I , 1989 , 4.

[13] Goryachev N.A., Conservative endodonty : Manual (Kazan: Medicine , 2002).

[14] Samsonov V.E. , Novoselytskyy V.L., Martyanov L.V., Specific composition and properties of microflora in chronic periodontitis , Kazan med.journal, 3, 1992, 183-184 .

[15] Tronstad L., Clinical Endodonty, (M.: MEDpress -inform , 2006).

[16] Roland Weiger O.A., Microbial infection of the mouth cavity, Quintessence, 2, 1995, 71-78

[17] The study of the specific activity of antimicrobial drugs. Guidelines , DFT MH of Ukraine , protocol № 9 dated 30.10 .2003 . 